\title{
Desert kites in the Tripolitania region: new evidence from satellite imagery
}

Gianna Giannelli ${ }^{1, *} \&$ Fabio Maestrucci ${ }^{1, *}$

Recent archaeological survey has revealed large numbers of stone structures, known as desert kites, in north-western Libya. The numbers of these structures and their evident adaptation over time demonstrate a longevity of use and a high degree of specialisation and cooperation among the people who built them.

Keywords: Africa, Libya, prehistory, hunting, desert kites

\section{Introduction}

In north-western Libya, a new and surprising concentration of stone structures has recently been discovered. Structures such as these are well documented in the Middle East, dating to around the fourth to second millennia BC and are known as 'desert kites' (Betts \& Burke 2015); these were probably used for hunting purposes or for corralling semi-domestic or domestic species. For the first time, however, structures with converging antennae that also feature a central wall have been found in Africa. Recent research has allowed us to increase the survey of these structures considerably, and, to date, around 1050 have been recorded across the Hamada al Hamra and eastern Tripolitania. The use of Google Earth imagery has also revealed other archaeological features including some ogival enclosures (pointed arch structures).

\section{New discoveries}

After the discovery of 330 structures on the Hamada al Hamra plateau (Giannelli \& Maestrucci 2018), another survey was undertaken in the south-east region of Adrar Nafusah (Jebel Gharbi), between Mizdâ and sebkha Tawargha (Figure 1). A high concentration of structures were identified in this survey, scattered among the most important wadis such as Sofeggin, Merdum and Zemzem. The most common form resembles a 'cone' or 'funnel', but several structures are characterised by a median line between the two convergent antennae, a feature also identified in some types of desert kites built in the basaltic areas of Jordan and Syria (Echallier \& Braemer 1995: 45-46). This median line, defined in the literature as a "central guiding wall" (Kempe \& Al-Malabeh 2012: 58), is probably designed to contain the movement of animals, avoiding their dispersion and allowing segregation (Figure 2). For example, in large complexes that are spread over different elevations in the landscape, the central wall

1 v.le Giotto 7, Empoli, Italy

* Author for correspondence (Email: ggfmae@gmail.com)

(C) Antiquity Publications Ltd, 2019

ANTIQUITY 93 371, e26 (2019): 1-9

https://doi.org/10.15184/aqy.2019.154 


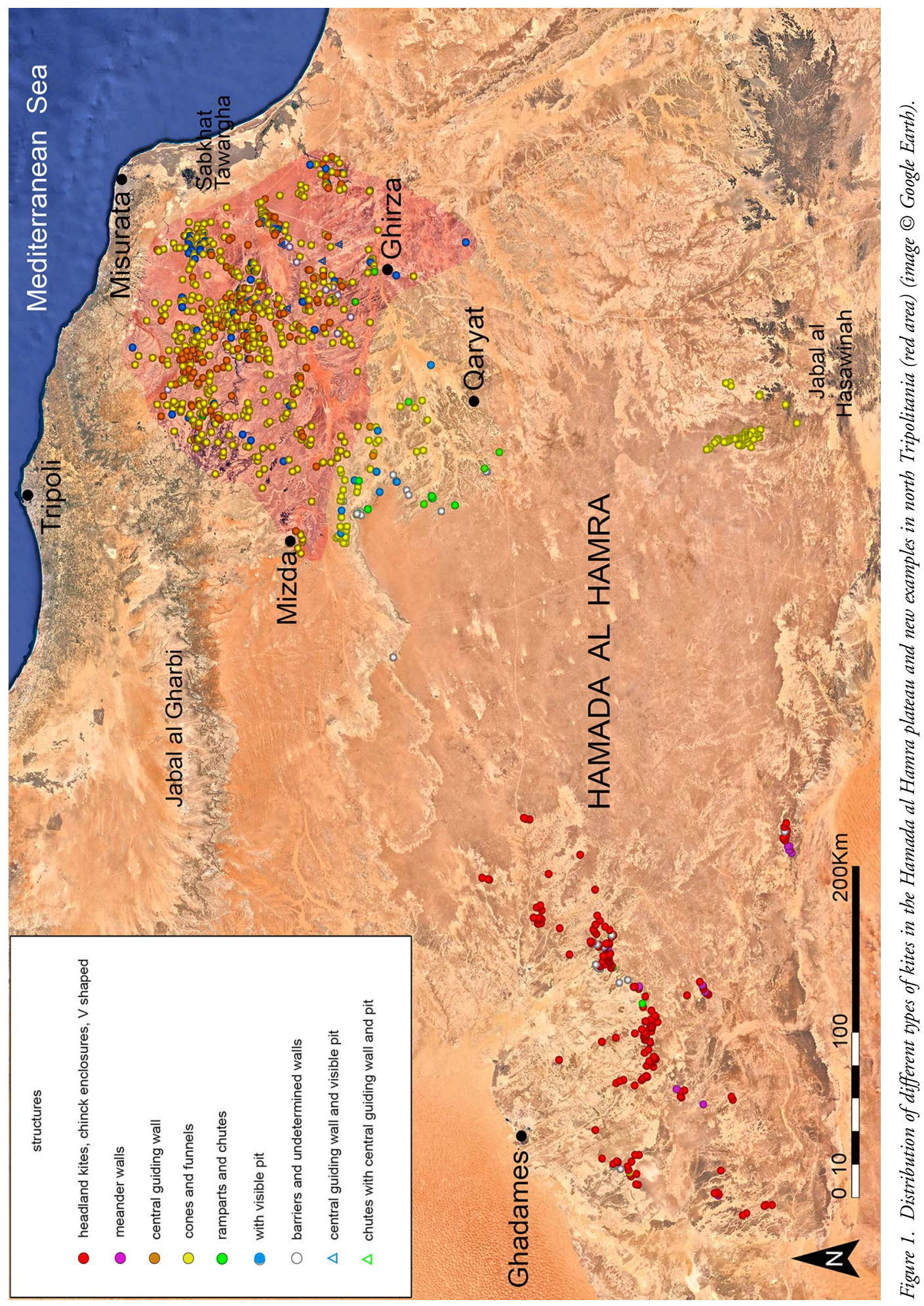

(C) Antiquity Publications Ltd, 2019 


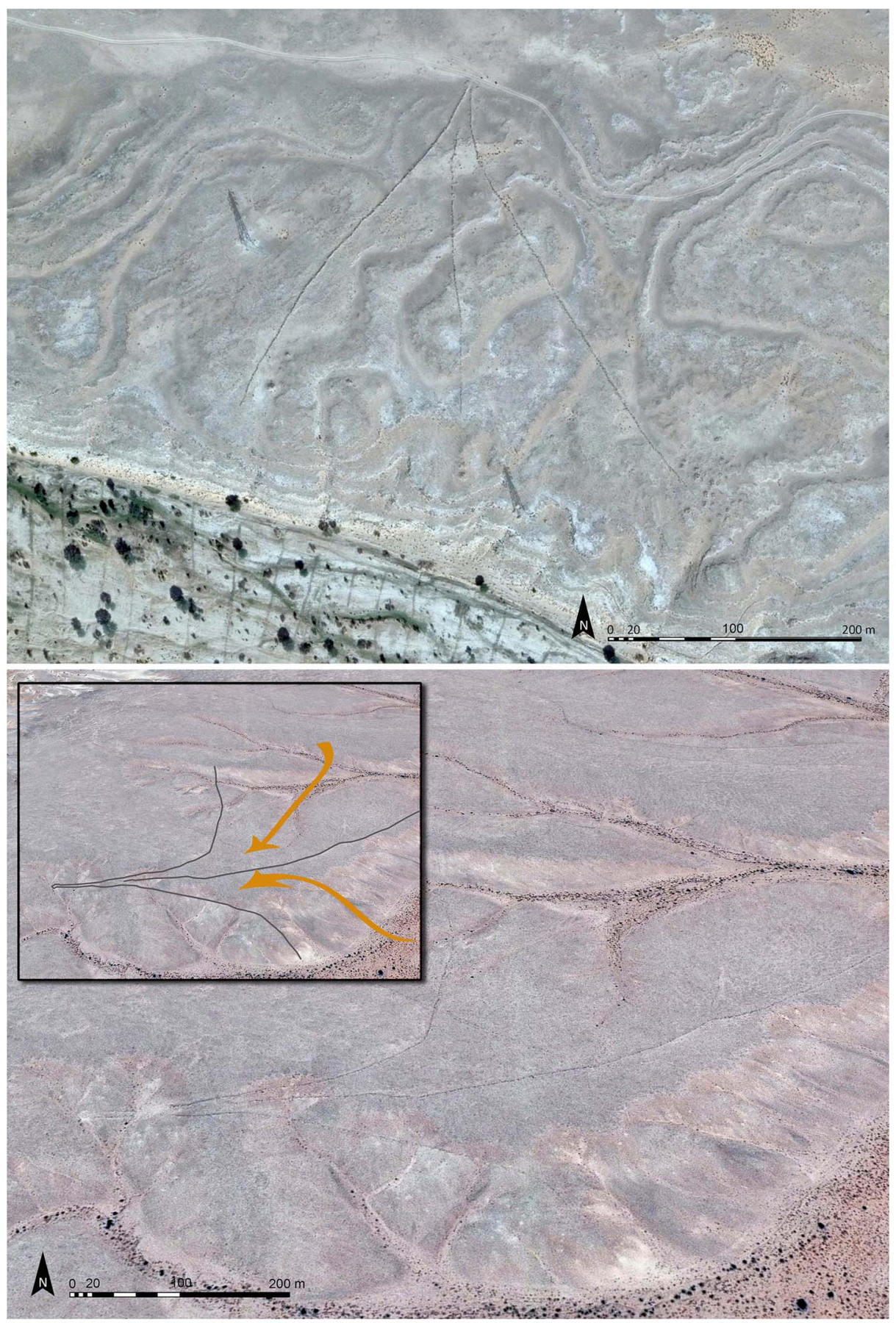

Figure 2. Top) a kite with the so-called' 'central guiding wall'; bottom) the central wall allows the channelling of animals coming from different directions (images () Google Earth). 

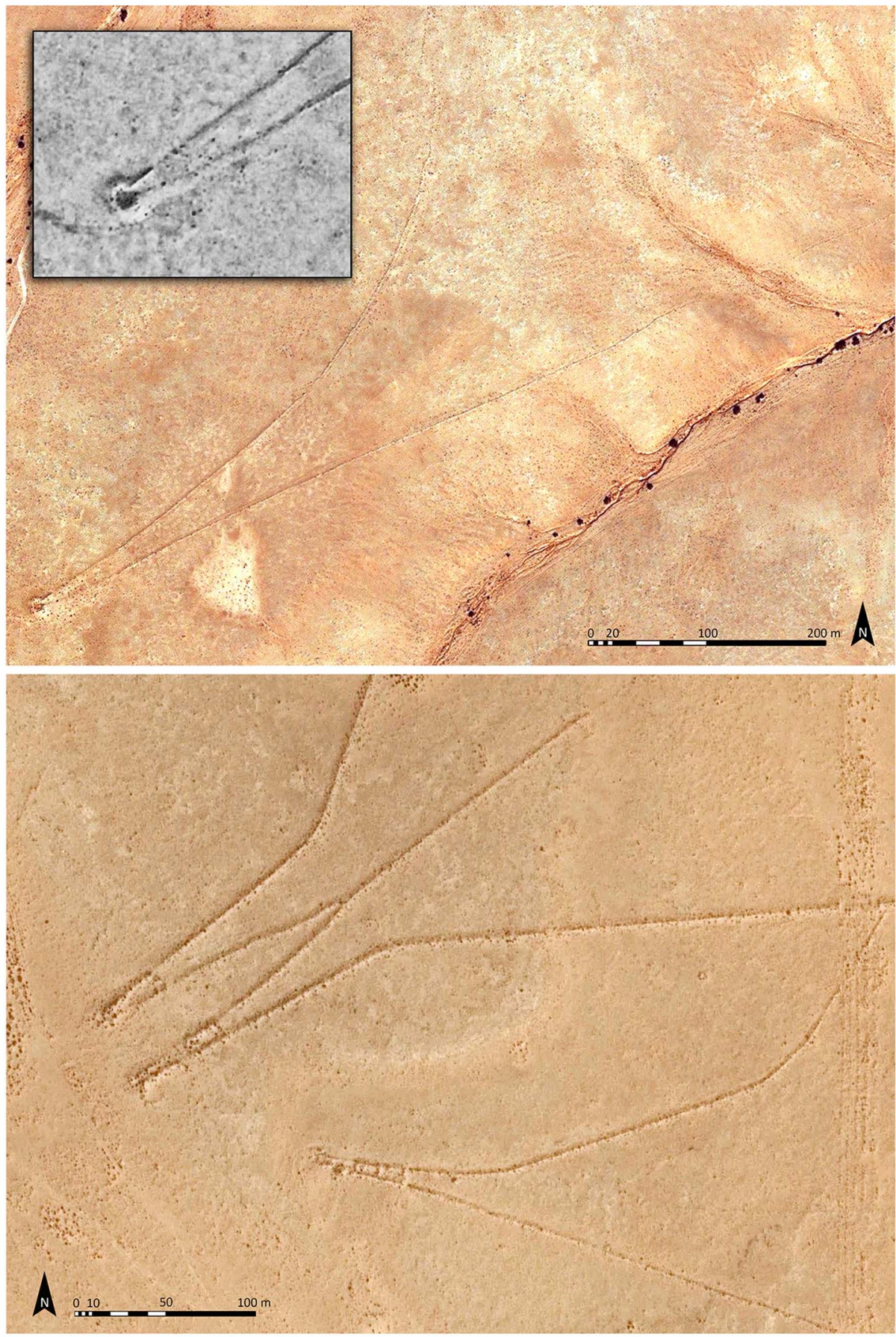

Figure 3. Top) detail of a pit at the apex of a kite trap; bottom) quadrangular chambers incorporated at the apex of the converging antennae (images (C) Google Earth).

(C) Antiquity Publications Ltd, 2019 
allows for animals coming from different directions to be guided towards the point of capture (Figure 2).

A study of numerous structures suggests that animals were channelled towards a pit dug at the convergence of the antennae, which was not visible to the animals as it was hidden by a depression or slope. From the satellite images, the pit generally appears circular or subcircular, with a diameter ranging between three to eight metres (Figure 3), but it is not easy to determine the original dimensions as sediment accumulates over time, reducing the apparent size. In a very few cases, the capture area has a quadrangular shape at the end of the convergence of the antennae (Figure 3).

Sometimes the antennae do not converge on a pit, but are directed towards a natural geographical drop, such as the edge of a wadi or a depression in the ground, as seen with the 'chute' of the desert kites of the Hamada al Hamra (Giannelli \& Maestrucci 2018), the Negev and Sinai (Holzer et al. 2010; Bar-Oz et al. 2011; Nadel et al. 2013). In addition to pits or mobile devices such as nets or shrubs, aquatic environments, where the prey would have been more vulnerable, may also have been employed. In these cases, natural water sources such as lakes or rivers may have been used as the trap, in that animals were driven into the water where they were then killed. To ensure or increase the effectiveness of the traps, hunters probably changed the shape of the structures over time. This could explain the construction of additional walls of variable lengths and orientations built both within and outside of the antennae walls. Geomorphological analysis reveals that the structures were built mainly in areas with relatively flat landscapes and much less frequently on plains and in mountainous regions. The type of prey, their number and seasonal movement would probably have determined the concentration of traps in an area. This also explains the presence of systems composed of three to four structures either adjacent or connected to one another, and sometimes of different sizes and orientations (Figure 4). The survey revealed unusual archshaped structures near the traps in some areas. The greatest concentration extends over the top of a long and narrow tabular relief west of the Tininai wadi, a tributary of the Sofeggin (Figure 5). Here, around 270 structures were identified, but their number may be greater given the difficulty in detecting them due to their narrow wall construction and poor image resolution. The structures mainly have a pointed arch shape, an opening ranging between 25 and 40 metres and a length, calculated from the apex to entrance, of between 28 and 35 metres. They vary in orientation. No additional features that could be identified as devices for guiding or blocking animals are visible in the images, but the high number of these complexes identified here and at other sites is evidence of an important, if unclear, function. The hypothesis that these are protostructures linked to hunting or food subsistence cannot be ruled out.

\section{Conclusions}

It is to be hoped that future multidisciplinary research will help us to understand the origin, evolution and spread of these structures, and dating should be possible by analysing the archaeology of the region such as probable settlements and inhumations, which are sometimes found in contact with the trap complexes. Landscape-management features such as the stone barrages erected next to some of these traps, and used for so-called "flood-water farming" (Trousset 1986: 102) (Figure 6), make them redundant and may offer a terminus

(C) Antiquity Publications Ltd, 2019 
Gianna Giannelli \& Fabio Maestrucci
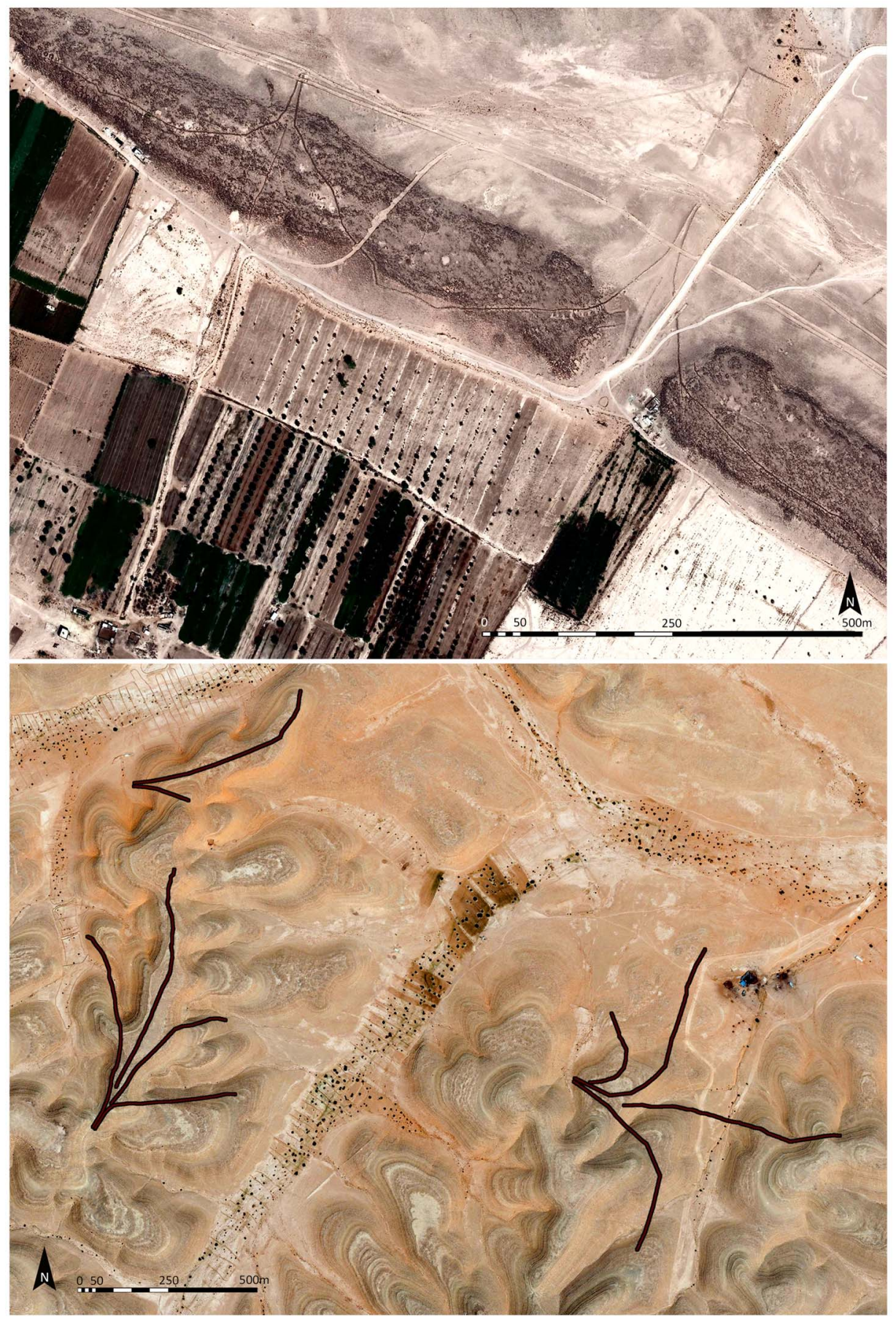

Figure 4. Top) two contiguous kites, both with a central wall; bottom) a group of kites consisting of three structures of different sizes and orientations; black lines show the shape of the structures (images () Google Earth).

(C) Antiquity Publications Ltd, 2019 


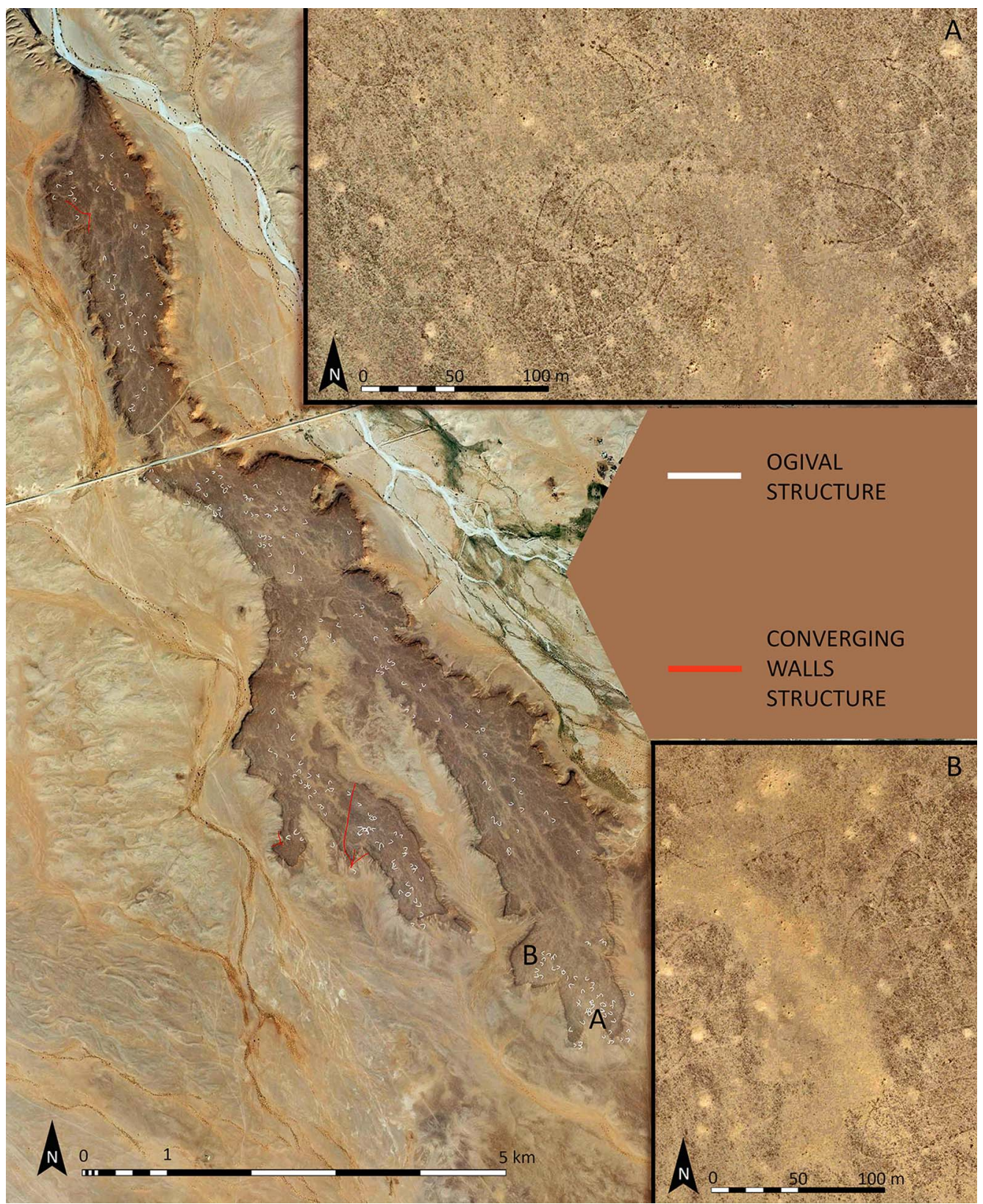

Figure 5. A group of around 270 ogival structures; insets $A$ and $B$ detail the structures in an area south-west of Tininai village (images () Google Earth).

ante quem of around the first century $\mathrm{AD}$ for the use of these kites. The quantity, variety and geographic spread of desert kites highlight both their importance and the high degree of specialisation and organisation achieved by the communities that created them. Throughout prehistory, hunting is believed to have held important symbolic and social value (Sidéra et al. 


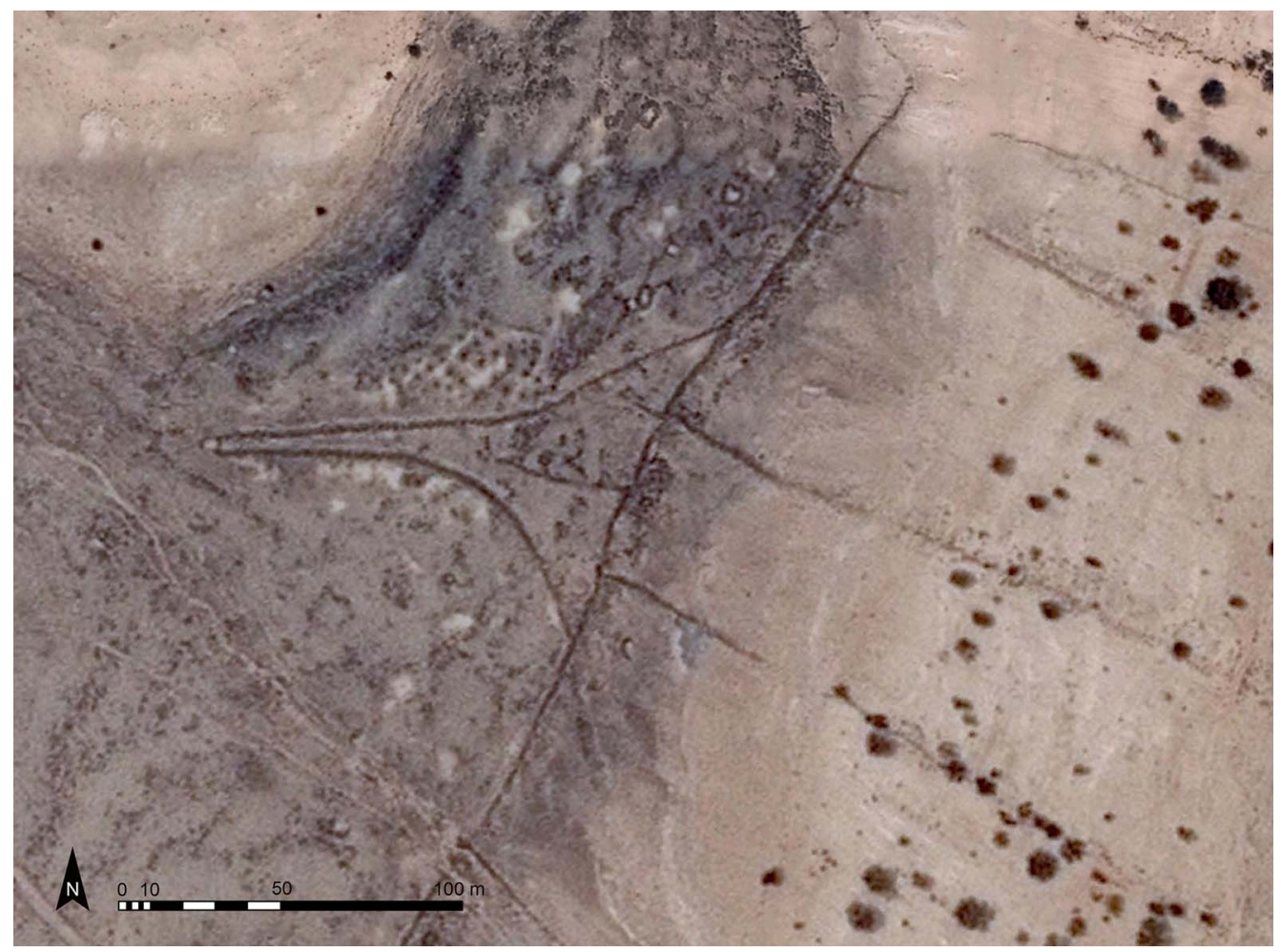

Figure 6. Stone barriers erected for agricultural purposes prevent access into the structure, revealing that the kites were not in use by this time (images () Google Earth).

2006); it is probable then that the use of kites for hunting endured over time. Changes in weather patterns and socio-economic factors in the region may have led to modifications in the function of these structures as they were adapted to different needs. They are probably among the oldest and largest stone-built structures surviving in Libya, which suggests a longevity of use and the cooperation of different groups for access to food resources. The exceptional number of structures discovered so far, while still provisional, is important evidence that the kite phenomenon in North Africa and the Sahara may hold opportunities for new perspectives in archaeological and anthropological research.

\section{References}

Bar-Oz, G., D. Nadel, U. Avner \& D. Malkinson. 2011. Mass hunting game traps in the southern Levant: the Negev and Arabah 'desert kites'. Near Eastern Archaeology 74: 208-15.

https://doi.org/10.5615/neareastarch.74.4.0208

Betts, A. \& D. Burke. 2015. Desert kites in Jordan -a new appraisal. Arabian Archaeology and Epigraphy 26. 74-94.

https://doi.org/10.1111/aae.12062
Echallier, J. \& F. Braemer. 1995. Nature et fonctions des 'desert kites', données et hypothèses nouvelles. Paléorient 21: 35-63. https://doi.org/10.3406/paleo.1995.4608

Giannelli, G. \& F. Maestrucci. 2018. Desert kites in the central Sahara. A preliminary report through satellite imagery. Antiquity Project Gallery 92(364): 1-7. https://doi.org/10.15184/aqy.2018.151

Holzer, A., U. Avner, N. Porat \& L. Kolska-Horwitz. 2010. Desert kites in the

(C) Antiquity Publications Ltd, 2019 


\section{Desert kites in the Tripolitania region}

Negev Desert and northeast Sinai: their function, chronology and ecology. Journal of Arid Environments 74: 806-17. https://doi:10.1016/j.jaridenv.2009.12.001

Kempe, S. \& A. Al-Malabeh. 2012. Distribution, sizes, function and heritage importance of the Harrat Al Shaam desert kites: the largest Prehistoric stoneworks of mankind? $15^{\text {th }}$ International Symposium on Vulcanospeleology, March 15-22, 2012: 57-66. Zarka: Hashemite University.
Nadel, D., G. Bar-Oz, U. Avner, D. Malkinson \& E. BOARETTO. 2013. Ramparts and walls: building techniques of kites in the Negev Highland. Quaternary International 297: 147-54. https://doi.org/10.1016/j.quaint.2012.11.037

Sidéra, I., E. Vila \& P. Ericson. 2006. La chasse. Pratiques sociales et simboliques. Paris: De Boccard.

Trousset, P. 1986. De la montagne au désert. Limes et maîtrise de l'eau. Revue de l'Occident musulman et de la Méditerranée 41-42: 90-115. https://doi:10.3406/remmm.1986.2111

Received: 3 December 2018; Revised: 5 March 2019; Accepted: 13 March 2019 